\title{
High Accumulation of Elements in the Kidney of the Marine Bivalve Cyclosunetta menstrualis
}

\author{
Toshiaki Ishii, ${ }^{* 1}$ Kunio Ikuta, ${ }^{* 2}$ Tsuguo Otake, ${ }^{* 3}$ Masako Hara, ${ }^{* 3}$ \\ Masafumi Ishikawa, ${ }^{* 1}$ and Taku Koyanagi*1
}

(Accepted June 26, 1985)

\begin{abstract}
Distribution of eighteen elements in the soft part of the marine bivalve Cyclosunetta menstrualis was examined by means of inductively coupled plasma atomic emission spectroscopy, atomic absorption spectrophotometry, and electron probe X-ray microanalysis. The highest concentration was found in the kidney for $\mathrm{Mg}, \mathrm{Ca}, \mathrm{Sr}, \mathrm{P}, \mathrm{Mn}, \mathrm{Fe}, \mathrm{Co}, \mathrm{Ni}, \mathrm{Zn}, \mathrm{Cd}, \mathrm{Sn}$ and $\mathrm{Pb}$. Especially, the manganese concentration in the kidney was $6820 \pm 1760 \mu \mathrm{g} / \mathrm{g}$ wet weight, which accounted for more than 90 percent of the total manganese in the soft part.

Extracellular granules of various sizes were observed in the lumen of the kidney tubules by light and electron microscopy. The scanning electron micrograph indicated that large sized granules $(10-200 \mu \mathrm{m})$ were composed of numerous fine $(0.1-1.0 \mu \mathrm{m})$ and small $(1.0-10 \mu \mathrm{m})$ sized granules. Many spherical substances and black concentric layers were observed inside the large granules. The granules contained extremely high levels of $\mathrm{Mg}, \mathrm{Ca}, \mathrm{P}, \mathrm{Mn}, \mathrm{Fe}, \mathrm{Zn}$ etc. For example, the concentrations of manganese and zinc in the dried granules were $44200 \pm 15600 \mu \mathrm{g} / \mathrm{g}$ and $22800 \pm 1600 \mu \mathrm{g} / \mathrm{g}$, respectively. It was concluded that the high accumulation of certain elements in the kidney resulted from the existence of metal-containing granules.
\end{abstract}

Bioaccumulators of specific elements have been used to monitor the levels of pollutant metals in the marine environment. High accumulation might suggest a relation with the special detoxication ability or the existence of characteristic intracellular ligands which the accumulators possess in their bodies. It has been reported that distributions of heavy metals are not uniform among the tissues and in the cells of marine organisms. For example, the concentration of copper in the branchiae of the polychaete Melinna palmata represents $30-40 \%$ of the total body burden, although these organs account for only $3-4 \%$ of the dry body weight. ${ }^{1)}$ The concentration of cadmium in the hepatopancreas of the lobster Panulirus japonicus is two thousand times higher than that in the abdominal muscle. ${ }^{2)}$ Reports on the subcellular localization of heavy metals describe that concretions in the kidney epithelial cells of the bay scallop Argopecten irradians contain large amounts of calcium, phosphorus, magnesium, manganese and zinc, ${ }^{3)}$ and that the concentric layers of intracellular granules in the hepatopancreas of the shore crab Carcinus maenas contain calcium, phosphorus, magnesium and lead.4)

In this report, the distribution of eighteen elements in the soft part of the marine bivalve Cyclosunetta menstrualis was examined by means of inductively coupled plasma atomic emission spectroscopy (ICP-AES), atomic absorption spectrophotometry (AAS) and electron probe X-ray microanalysis.

In addition, the kidney was examined morphologically by an optical, a scanning and a transmission electron microscope in order to clarify causes of the high accumulation of elements.

\section{Material and Methods}

\section{Material}

Cyclosunetta menstrualis, $67-73 \mathrm{~mm}$ in shell length and $68-87 \mathrm{~g}$ in whole body weight, were collected from the offshore area of Ibaraki Prefecture (Japan) from October 1983 to July 1984. Twenty five individuals were dissected into various tissues such as adductor muscles, kidneys, mantles, gills, foot, etc.

*1 Division of Marine Radioecology, National Institute of Radiological Sciences, Isozaki 3609, Nakaminato 311-12, Japan (石井新明, 石川昌史, 小柳 卓: 放射線医学総合研究所海洋放射生態学研究部).

*2 Faculty of Agriculture, Miyazaki University, Kumano, Miyazaki889-21,Japan(生田國雄: 宫崎大学農学部).

*3 Ocean Research Institute, University of Tokyo, Nakano, Tokyo 164, Japan (大竹二雄, 原 政子: 東 京大学海洋研究所). 
Determination of Elements by ICP-AES and AAS

The dissected tissues were dried at $70^{\circ} \mathrm{C}$ and digested with nitric and perchloric acids. The digests were diluted with $0.5 \mathrm{~N}$ nitric acid to a volume of $100 \mathrm{~m} /$. High purity inorganic compounds (sodium, potassium, calcium, magnesium and phosphorus) were purchased from Johnson Matthey Chemicals Ltd. and Spex Industries Inc. for matrix matching. Water used in this experiment was purified by a Barnstead NANOpure D-2794 four-module system.

The concentrations of $\mathrm{Na}, \mathrm{K}, \mathrm{Mg}, \mathrm{Ca}, \mathrm{Sr}, \mathrm{S}, \mathrm{P}$, $\mathrm{Mn}, \mathrm{Fe}, \mathrm{Cu}, \mathrm{Zn}, \mathrm{Al}$ and $\mathrm{Sn}$ were measured using a Shimadzu ICPQ-1012W inductively coupled plasma atomic emission spectrometer. The spectrometer is equipped with a Paschen-Runge mount polychrometer which has a Rowland circle of $100 \mathrm{~cm}$. The reciprocal linear dispersion of $0.37 \mathrm{~nm} / \mathrm{mm}$ at $180.5 \mathrm{~nm}$ is provided by a master holographic grating with 2700 grooves $/ \mathrm{mm}$. Operating conditions were almost the same as those described previously. ${ }^{2}$ )

Cobalt, nickel, cadmium, lead, and rubidium were analyzed using a Perkin-Elmer Model 5000 atomic absorption spectrophotometer equipped with an HGA-400 programmer and an AS-40 auto sampler. The ICP-AES could not be used to determine these elements because of poor detection limits.

Preparation of Specimens for Elemental Analyses by Electron Probe X-ray Microanalyzers (EPMA)

For the analysis by EPMA with an energy dispersive X-ray detector (EDX), small pieces (approximately $1 \times 1 \mathrm{~mm}$ ) of the kidney of $C$. menstrualis were fixed for $2 \mathrm{~h}$ in cold fixative which contained $2 \%$ paraformaldehyde and $2 \%$ glutaraldehyde in $0.1 \mathrm{M}$ sodium phosphate buffer (pH 7.4). Then, they were post-fixed in $2 \%$ osmium tetroxide. Specimens were dehydrated through graded ethanols and embedded in Epon 812. Sections of $0.1 \mu \mathrm{m}$ thickness were placed on an aluminum, a molybdenum and a titanium grid. Elemental analysis (point analysis) was performed by a Hitachi H-600/H-6010 electron microscope with a Kevex $7000 Q$ energy dispersive X-ray analyzer.

For the analysis by EPMA with a wavelength dispersive X-ray detector (WDX), freeze-dried sections of the kidney were cut at $20 \mu \mathrm{m}$ in thickness with a Lipshaw Model 1900 cryostat microtome. Linear scanning analysis was carried out using a Hitachi X-650 scanning electron microscope.

\section{Observation of the Kidney by Microscopes}

Specimens for light microscopy were prepared by decalcifying in $1 \%$ formic acid for 2 or 3 days because granules in the kidney were exceedingly hard. Sections of $5 \mu \mathrm{m}$ thickness were stained with hematoxylin and eosin.

Specimens for transmission electron microscopy were fixed and embedded by the same procedure as that of EPMA with EDX, as mentioned above. Ultra-thin sections, stained with uranyl acetate and lead citrate, were examined in a JEOL JEM 100-CX electron microscope.

\section{Separation of Granules from the Kidney}

The size of extracellular granules in the lumen of the kidney tubules ranged from 0.1 to $200 \mu \mathrm{m}$. One large sized granule was generally present in one lumen, though numerous fine and small sized granules were observed in the same lumen. Most of the small $(1-10 \mu \mathrm{m})$ and the large $(10-200 \mu \mathrm{m})$ granules were separated from the soft tissue of the kidney by shaking or simple homogenizing in seawater. Granules collected on Nuclepore filters (pore size $1.0 \mu \mathrm{m}$ ) were dried at $110^{\circ} \mathrm{C} . \mathrm{A}$ large number of fine granules $(0.1-1.0 \mu \mathrm{m})$ might have been lost by decantation to remove cell debris or filtration.

\section{Results and Discussion}

\section{Distribution of Elements in the Soft Part}

The concentrations of elements in various tissues of $C$. menstrualis are shown in Table 1. The highest concentration is found in the kidney for $\mathrm{Mg}, \mathrm{Ca}, \mathrm{P}, \mathrm{Sr}, \mathrm{Mn}, \mathrm{Fe}, \mathrm{Zn}, \mathrm{Co}, \mathrm{Ni}, \mathrm{Cd}, \mathrm{Sn}$, and $\mathrm{Pb}$. Especially, the manganese is concentrated in the kidney about six thousand times higher than in the foot. More than $90 \%$ of the total soft part burden of manganese is accumulated in the kidney which accounts for only $2 \%$ of the total weight of the soft part. The concentration factor of manganese by the kidney is $2 \times 10^{3}$ when calculated by using the concentration of manganese in coastal water off Ibaraki Prefecture $\left(2.94 \mu \mathrm{g} / l^{*}\right)$.

The major elements are usually considered to be distributed uniformly among the soft tissues of marine organisms. In the case of this species, however, the concentrations of magnesium, calcium and phosphorus in the kidney are more

* This manganese concentration which we measured by neutron activation analysis was cited in the Annual Report of National Institute of Radiological Sciences NIRS-AR-17. 


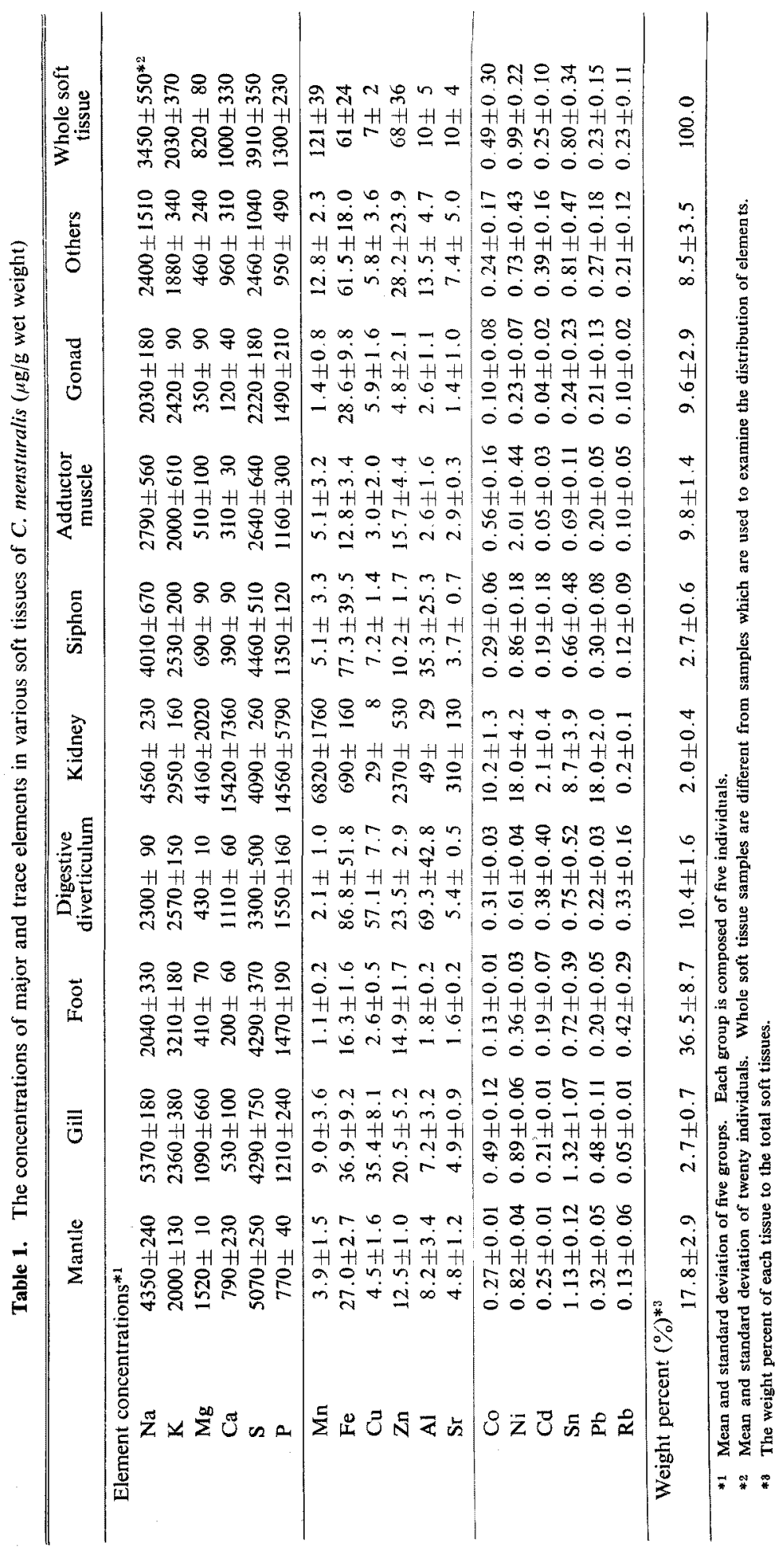


Table 2. The concentrations of elements in five granule samples*1 isolated from the kidney of C. menstrualis ( $\mu \mathrm{g} / \mathrm{g}$ dry weight)

\begin{tabular}{|c|c|c|c|c|c|c|}
\hline & No. 1 & No. 2 & No. 3 & No. 4 & No. 5 & Mean \pm s.d. \\
\hline $\mathrm{Na}$ & 5420 & 6110 & 5840 & 5730 & 4290 & $5480 \pm 630$ \\
\hline $\mathrm{K}$ & 1210 & 1590 & 2110 & 2330 & 1030 & $1650 \pm 500$ \\
\hline $\mathrm{Mg}$ & 31500 & 30900 & 20000 & 37400 & 32600 & $30500 \pm 5700$ \\
\hline $\mathrm{Ca}$ & 133000 & 134000 & 108000 & 149000 & 131000 & $131000 \pm 13000$ \\
\hline $\mathrm{Sr}$ & 3050 & 3070 & 3150 & - & 3120 & $3100 \pm$ \\
\hline$(\mathrm{Ba})^{* 2}$ & 110 & 130 & 190 & 75 & 96 & $120 \pm$ \\
\hline $\mathrm{P}$ & 124000 & 118000 & 106000 & 128000 & 119000 & $119000 \pm 7000$ \\
\hline$(\mathrm{Cr})^{* 2}$ & 26 & 27 & - & 41 & 27 & $30 \pm$ \\
\hline $\mathrm{Mn}$ & 44400 & 20000 & 68200 & 49500 & 39000 & $44200 \pm 15600$ \\
\hline $\mathrm{Fe}$ & 4770 & 4720 & 12100 & 5540 & 4430 & $6310 \pm 2920$ \\
\hline Co & 53 & 59 & - & 20 & 49 & $45 \pm$ \\
\hline $\mathrm{Ni}$ & 110 & 95 & - & 69 & 140 & $104 \pm$ \\
\hline $\mathrm{Cu}$ & 92 & 200 & - & 59 & 98 & $112 \pm$ \\
\hline $\mathrm{Zn}_{\mathrm{n}}$ & 23200 & 24300 & 24500 & 20600 & 21200 & $22800 \pm 1600$ \\
\hline $\mathrm{Cd}$ & 13 & - & - & - & - & - \\
\hline Al & 450 & 410 & 230 & 550 & 440 & $420 \pm 100$ \\
\hline $\mathrm{Pb}$ & 270 & 290 & 360 & 320 & 280 & $300 \pm$ \\
\hline$(\mathrm{Ag})^{* 2}$ & 12 & 17 & - & 11 & 12 & $13 \pm$ \\
\hline Total & 371690 & 343920 & 350680 & 399250 & 356810 & 365180 \\
\hline
\end{tabular}

than ten times higher than those in the foot, gonad, etc.

We measured trace element concentrations in the kidney for ten species of Japanese marine bivalves which were collected off the Pacific coast. For example, the concentrations of manganese and zinc for Meretrix lamarcki were 1.5 and $18 \mu \mathrm{g} / \mathrm{g}$ wet weight, respectively. Those for Gomphina melanaegis were 0.82 and $66 \mu \mathrm{g} / \mathrm{g}$ wet weight, respectively. These two clams belong to the same family, Veneridae, as $C$. menstrualis and inhabit the same unpolluted sandy area $(2-10 \mathrm{~m}$ in water depth) off the coast of Ibaraki Prefecture. The other eight species also did not show high concentrations of manganese and zinc. Furthermore, the high accumulation of trace elements including manganese, zinc, strontium, cobalt, and nickel has not been previously reported for marine organisms in Japan.

It was concluded that $C$. menstrualis has the characteristic ability to accumulate elements at much higher concentrations than other Japanese marine organisms. We hope $C$. menstrualis can be used as an effective indicator for monitoring the levels of stable heavy metals and/or evaluating radiation dose from artificial radionuclides in the marine environment.

\section{Concentrations of Elements in the Granules}

The concentrations of elements in the granules are shown in Table 2. Significantly high concentrations of calcium, phosphorus, magnesium, manganese, and zinc are found in the dried granules. This suggest that high levels of these elements in the kidney (see Table 1) are attributable to the existence of the metal-containing granules. Meanwhile, the total amount of metals and phosphorus in the dried granules is only about 40 percent (see Table 2). Therefore, it is considered that metals exist in various chemical forms such as chloride, sulphide, carbonate or oxide in addition to phosphate. Furthermore, we suspect that water (e.g. the water of crystallization) and organic substances occupy a small part of the weight of the granules. Mason and Nott $^{5)}$ report in the review that intracellular granules isolated from the soft tissues of some gastropods contain $\mathrm{PO}_{4}{ }^{3-}$ and $\mathrm{CO}_{3}{ }^{2-}$ as the major anions and polysaccharide, protein and lipid as the organic components. Ghiretti et al. ${ }^{0)}$ indicate that large amounts of carbon, oxygen, hydrogen and phosphorus are contained in the nephroliths of the fan shell Pinna nobilis, and part of the nephrolith body is formed by organic materials.

In the case of $C$. menstrualis, chemical forms (including organometallic compounds) of metals in the granules are not known though the principal constituent of them is thought to be calcium phosphate. Therefore, we are examining the 


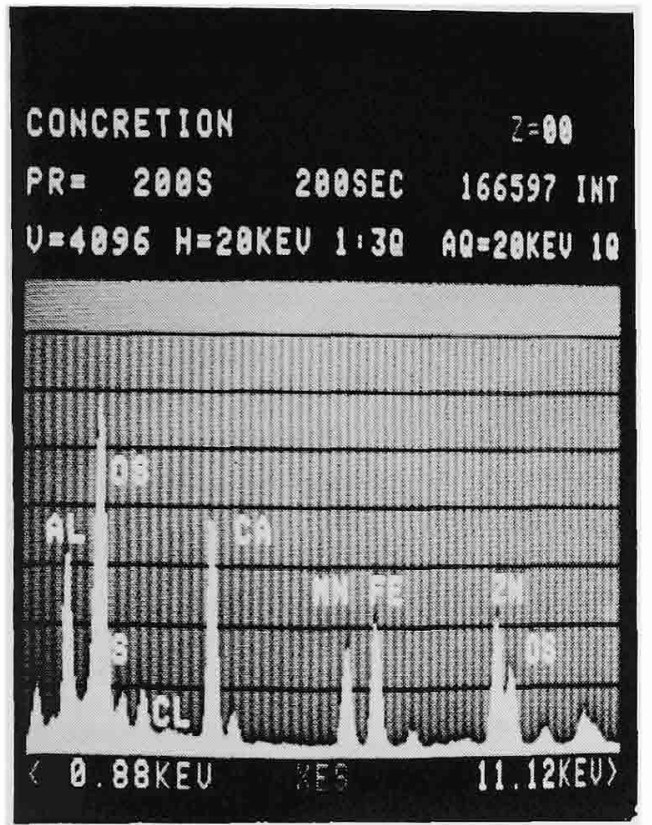

Fig. 1. X-ray spectrum obtained by EPMA with EDX for a fine sized granule in the lumen of the kidney tubule of $C$. menstrualis.

elemental composition of the granules in detail.

The manganese concentration in the dried kidney was calculated to be $25,700 \mu \mathrm{g} / \mathrm{g}$ from the dry/wet weight ratio $(26.5 \pm 3.7 \%)$. The total weight of the granules (average Mn concentration $44,200 \mu \mathrm{g} / \mathrm{g}$ dry weight) was estimated to occupy about 50 percent of the dry matter of the kidney, on the assumption that the contribution of the kidney tissues excluding granules to the total manganese was negligibly small or at most $10 \%$.

Marine bivalves have calcium-rich shells which are composed of a large quantity of calcium carbonate and a small quantity of organic compounds such as protein and polysaccharide. Concentrations of some elements in the shells of $C$. menstrualis are as follows: $449,000 \mu \mathrm{gCa} / \mathrm{g}, 7.6$ $\mu \mathrm{gP} / \mathrm{g}, \quad 2.2 \mu \mathrm{gMn} / \mathrm{g}, \quad 1.7 \mu \mathrm{gFe} / \mathrm{g}$ and $1.5 \mu \mathrm{gZn} / \mathrm{g}$ (dry weight). This means that the concentrations of phosphorus, manganese, iron and zinc in the shells were much lower than those in the granules. We are planning to study the difference in mechanisms of metal deposition between the two types of calcium compounds.

\section{Elemental Analyses by EPMA}

The X-ray spectrum (Fig. 1) obtained by EPMA with EDX for a fine granule (approximately 0.2
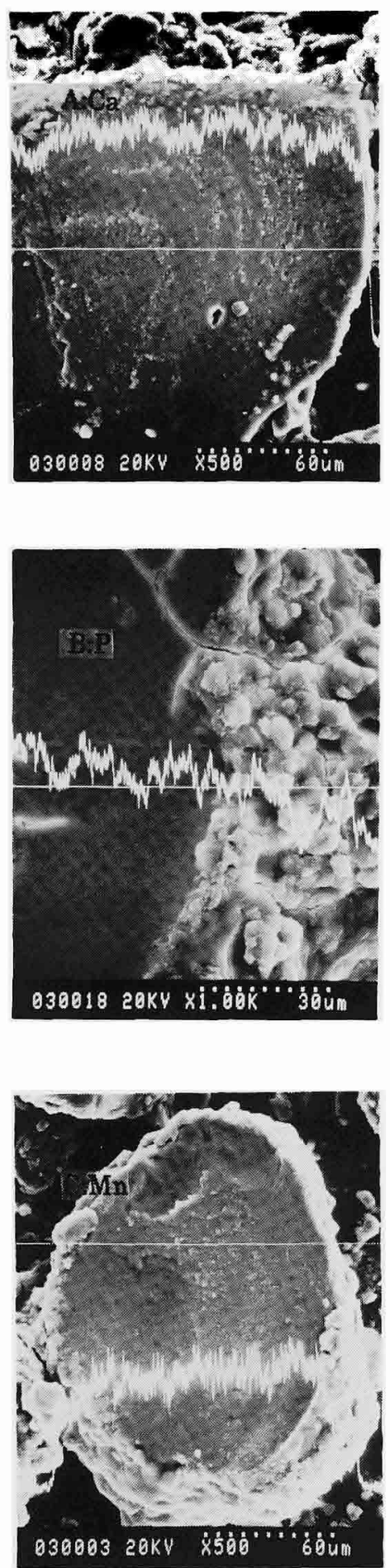

Fig. 2. Linear scanning analysis by EPMA with WDX for sectioned large sized granules. Fig. 2-A: calcium, -B: phosphorus, -C: manganese. 


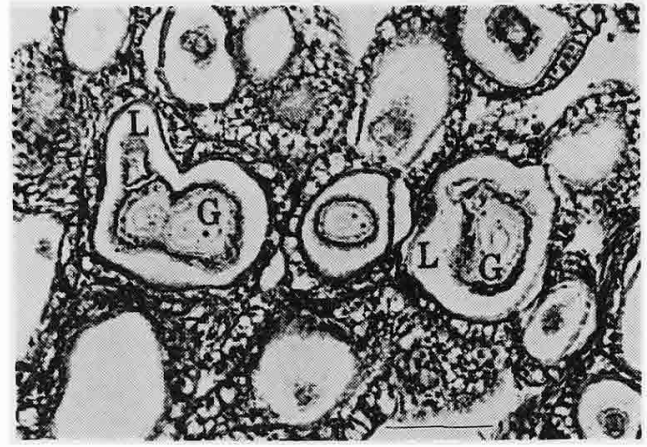

Fig. 3. Light micrograph of a cross section of the kidney indicates that concentrically structured granules (G) with various shapes exist in the lumen (L) of the kidney tubules. Scale bar represents $100 \mu \mathrm{m}$.

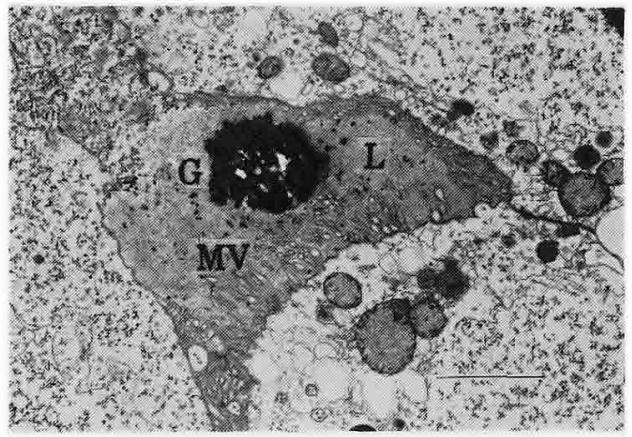

Fig. 5. Transmission electron micrograph of the kidney tubule, showing a small sized granule (G), lumen (L), and microvilli (MV). Scale bar represents $2 \mu \mathrm{m}$.

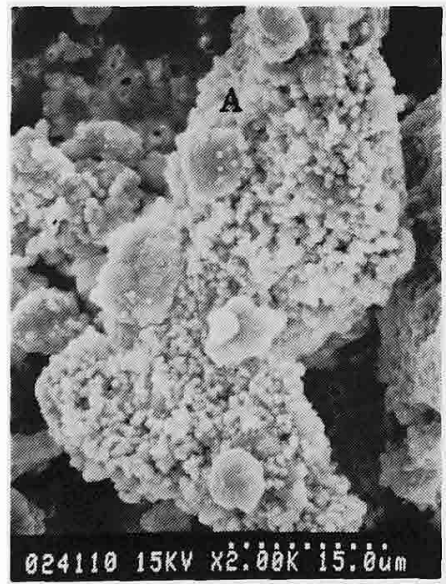

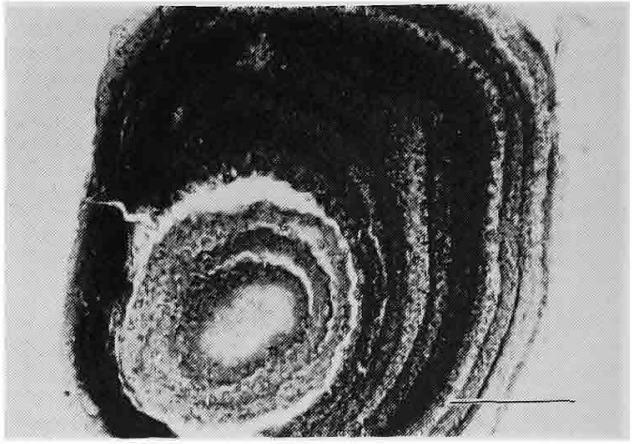

Fig. 4. Light micrograph of the internal structure of a large sized granule. Scale bar represents 50 $\mu \mathrm{m}$.

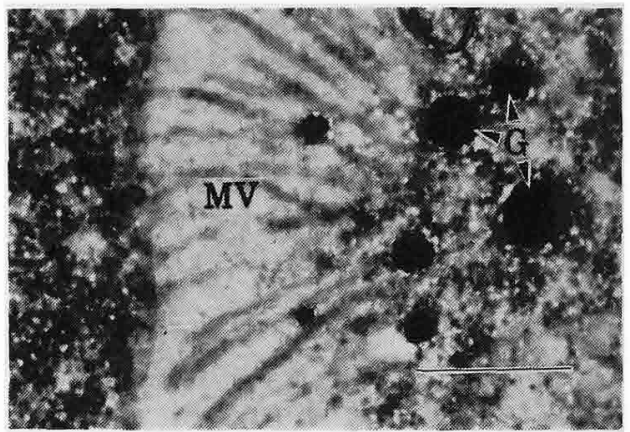

Fig. 6. Ultrastructure of the lumen of the kidney tubule, showing fine sized granules $(G)$ and microvilli $(\mathrm{MV})$. Scale bar represents $1 \mu \mathrm{m}$.

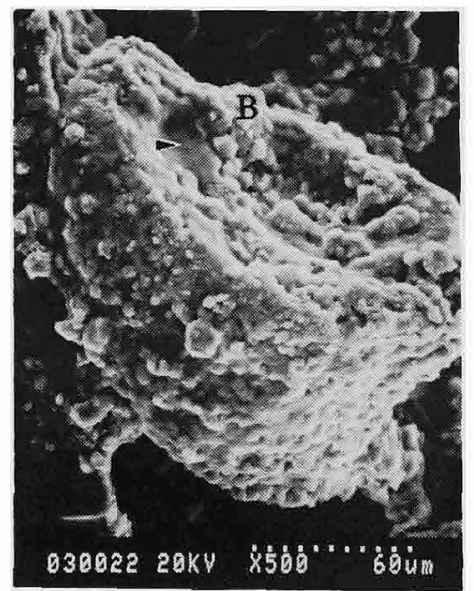

Fig. 7. Scanning electron micrographs for two large sized granules Fig. 7-A: a smaller granule, -B: a larger granule. 
$\mu \mathrm{m}$ in diameter) indicates that large amounts of calcium, manganese, iron and zinc are localized in the granule. The results of Table 2 and Fig. 1 suggest that the main metal composition of fine granules is similar to that of larger ones. Probably, fine granules develop into larger ones without any change in the elemental composition.

Though a high level of phosphorus is contained in the granule, the peak would be interfered by a characteristic X-ray (M $\alpha)$ of osmium. No significant peaks of calcium, manganese, iron or zinc were observed in the spectra of the nucleus, mitochondria, cytoplasm in kidney cells.

Fig. 2-A, B, C shows the result of linear scanning analyses by EPMA with WDX for sectioned granules. Calcium, phosphorus and manganese are distributed uniformly in the granules.

As discussed later, a concentric structure is observed inside the granules (Fig. 4). Concentric layers are thought to have no relation to the metals being studied. But additional studies on the relationship between concentric layers and metals need to be conducted though we think layers are composed of organic substances.

\section{Observation of the Kidney Tissue}

A pair of kidneys is located beside the posterior adductor muscle of $C$. menstrualis. Distinction of the kidney from other tissues is very easy because of its dark brown color.

Large extracellular granules with various shapes are observed in the lumens of tightly packed and twisted blind tubules in the kidney (Fig. 3). Several concentric layers are recognized in most granules when decalcified in a $1 \%$ formic acid solution.

Intracellular granules abundant in heavy metals are often present in various tissues of molluscs, but there are few reports about metal-containing extracellular granules. Ghiretti et $a l^{0}{ }^{0}$ report that a metal-rich stone appears in the renal cavity surrounded by a monolayer of secreting cells of $P$. nobilis. Mauri and Orlando ${ }^{7)}$ report that the wedge shell Donax trunculus can form extracellular renal concretions when reared under higher manganese levels than those in natural seawater.

Small round substances of various colors (mainly yellow) are observed in a large sized granule, as shown in Fig. 4. It is suggested that one large granule is an aggregate of many fine and small ones. The proximal layers have a naturally dark brown color and are not stained with hematoxylin and eosin. The eosinophilic distal layers indicate the presence of organic substances. Some black concentric layers and a white area similar to interstice are also observed. The relationship between the formation of the concentric structure and physiological functions of the kidney is under investigation. However, it is possible that the white area resulted from an artefact which occurred during fixation, decalcifying or sectioning.

In a transmission electron micrograph (Fig. 5) a small granule is found at the center of the lumen surrounded with microvilli. Many particles are observed inside the granule.

Electron-dense spherical granules are observed beside microvilli, as shown in Fig. 6. But no substances with a high electron density are present in the cytoplasm of kidney cells.

A scanning electron micrograph (Fig. 7) indicates that the large sized granules are composed of numerous fine and small sized ones. It is estimated that spaces between the fine granules were gradually packed by adhesion with new deposits like phosphate or organic substances while the fine granules basically keep the original spherical shape. For example, Fig. 7-B (arrow) indicates that the spherical shape appear to change into an uncertain one. But it is suspected that some interspaces containing liquid interstitial materials remain inside the granules.

These morphological aspects suggest that the spherical fine granules appear extracellularly beside microvilli and develop into larger granules while moving to the center of the lumen of the kidney tubules.

Further experiments are intensively in progress in our laboratory to examine the reasons why the metal-containing extracellular granules appear in the lumen of the kidney tubules of $C$. menstrualis. If the granules could be formed actively through biological processes, studies on their physiological roles might be very necessary to estimate the purpose for the granule formation. On the other hand, if the granules could be formed passively by abiotic pathways, the quantities and physico-chemical forms of elements when excreted from microvilli to the lumen will be important subjects in clarifying the mechanisms of metal deposition.

\section{References}

1) P. E. Gibbs, G. W. Bryan, and K.P. Pyan: $J$. Mar. Biol. Ass. U.K., 61, 707-722 (1981).

2) T. Ishii, R. Nakamura, M. Ishikawa, and $T$. 
Koyanagi: Bull. Japan. Soc. Sci. Fish., 51, 609617 (1985).

3) N. G. Carmichael, K. S. Squibb, and B. A. Fowler: J. Fish. Res. Board. Can., 36, 11491155 (1979).

4) S. P. Hopkin and J. A. Nott: J. Mar. Biol. Ass. U.K., 59, 867-877 (1979).
5) A. Z. Mason and J. A. Nott: Aquatic Toxicology, 1, 239-256 (1981).

6) F. Ghiretti, B. Salvato, S. Carlucci, and R. De Pieri: Experientia, 28/2, 232-233 (1972).

7) M. Mauri and E. Orlando: J. Exp. Mar. Biol. Ecol., 63, 47-57 (1982). 